\title{
Threshold Effects of Energy Price Changes*
}

\author{
Daan P. van Soest ${ }^{\mathrm{a}}$, Gerard H. Kuper ${ }^{\mathrm{b}}$, and Jan Jacobs ${ }^{\mathrm{c}}$ \\ DO NOT QUOTE
}

January 2000

\begin{abstract}
The effectiveness of policies to reduce the use of energy depend on the elasticity of substitution between the various inputs and on the rate of technological progress.

This paper presents a theoretical model emphasising energy investments' characteristics of uncertainty and irreversibility that result in hypotheses concerning the relative values of substitution parameters and rates of technological change in periods of high and increasing energy prices and in periods of low prices.

The theoretical model suggests that threshold level effects exist. Firms are induced to substitute away from energy only if prices of energy exceed a certain threshold level and they reverse the technology only if prices are low enough. Using panel data for the Dutch economy we do not find threshold effects in the level of energy prices.
\end{abstract}

Keywords: threshold effects, energy substitution, environmental policy JEL-classification: C23, D21, Q43

\footnotetext{
${ }^{*}$ We gratefully acknowledge the help of Hein Mannaerts and Henry van der Wiel (both CPB, Netherlands Bureau for Economic Policy Analysis) for providing us with data. We thank Erwin Bulte, Shelby Gerking, Willem van Groenendaal, Simon Kuipers, Michiel de Nooij and Aart de Zeeuw for useful comments on an earlier version of the paper. All errors are ours.

${ }^{a}$ Tilburg University, Department of Economics, P.O. Box 90153, 5000 LE Tilburg, The Netherlands, Email: d.p.vansoest@kub.nl Tel. (+31)13 4662072, Fax. (+31)13 4663042

${ }^{\mathrm{b}}$ University of Groningen, Department of Economics, SOM, P.O. Box 800, 9700 AV Groningen, The Netherlands, Email: g.h.kuper@eco.rug.nl Homepage: http://www.eco.rug.nl/medewerk/kuper Tel. (+31)50 3633756, Fax. (+31)50 3637337

${ }^{\mathrm{c}}$ University of Groningen, Department of Economics, SOM, P.O. Box 800, 9700 AV Groningen, The Netherlands, Email:.j.p.a.m.jacobs@eco.rug.nl Homepage: http://www.eco.rug.nl/medewerk/jacobs Tel. (+31)50 3633681, Fax. (+31)503637337
} 


\section{Introduction}

Governments of most developed countries aim to substantially reduce energy use to limit the emission of greenhouse gases (such as carbon dioxide). The effectiveness of taxing energy use depends on the substitution elasticity between inputs in production and on technological progress. Analysis of past experience may give insight in the potential effectiveness of energy taxation to induce a decrease in energy use.

Examination of the data indicates that the 1973-1994 period can be divided in two sub-periods. From 1973 to 1986, energy prices went up, while prices have been observed to fall quite substantially in later years, as can be seen from Figure $1 .{ }^{1}$

\section{< Insert Figure 1 about here >}

This subdivision may be important as the economic consequences of energy price increases and decreases are generally not symmetric. The literature on the potential causes of asymmetric responses to energy price increases and decreases has focused on the importance of irreversibility. If adjustment to changes in relative prices involves adaptation costs, economic agents have an incentive to postpone the adjustment. The incentive to postpone is even stronger when there is uncertainty about the persistence of the change. If adjustments are costly and the future is uncertain, the option value of waiting increases because new information is likely to arrive over time, which may exceed the foregone benefits of adjusting straightaway. This idea has been applied at various levels in the economy. The literature focusing at the sectoral level, initiated by Hamilton (1988), attacks the idea that production factors are able to relocate smoothly from one sector to another. If production factors (mainly capital and labour) are specialised, it may be optimal not to immediately leave adversely affected sectors and to move to positively affected sectors, but to remain unemployed and wait for conditions to improve. At the micro level, firms are likely to postpone irreversible investment expenditures on both energy-saving technologies and their reversal towards energy-intensive technologies (see for example Bernanke, 1983). This means that firms will not respond immediately to energy price increases; but if they have responded, energy prices will have to fall substantially before the investment is reversed.

Empirical studies seem to corroborate this explanation of asymmetric responses. At the micro-economic level there is evidence pointing to the fact that firms and consumers adapt faster (and stronger) to energy price increases than to price decreases (e.g. Bacon, 1991;

\footnotetext{
${ }^{1}$ Sectoral energy prices have been calculated on the basis of the share of the various energy carriers in a sector's energy use.
} 
Borenstein et al., 1997; Gately, 1992; Kirchgässner and Kübler, 1992; Mork, 1989; Ryan et al., 1996). At the macro-level, asymmetries may also be important. It has been observed that economic activity is more strongly affected by increases in the energy price than by decreases (Dargay and Gately, 1994; Gardner and Joutz, 1996; Mork et al., 1994; Mory, 1993; Smyth, 1993). However, not all price increases will have an equally strong impact on investments in energy-saving technologies. If energy prices increase after a period of low prices, the change is merely a recovery that is unlikely to induce additional investments in energy efficiency. Only "all time highs" will induce new investments in energy efficiency (Hamilton, 1996). If such an asymmetric response exists, it has important policy implications. Currently, energy prices are relatively low after a period of significant price increases (1973-1986). This means that (part of the) industry has already geared its technology to higher energy prices in the past. ${ }^{2}$ Increasing energy tax rates now (as part of environmental policy) is therefore expected not to have a strong impact on investment behavior and technology choice, and thus result in only modest reductions in energy use. More likely, firms are forced to simply incur the rise in costs. This means that in order to achieve a substantial reduction in energy use, energy prices should be increased considerably with potentially high costs in terms of, for example, international competitiveness. However, in the post-1986 period, energy prices are much lower and also less subject to fluctuations. Given the positive correlation between the level of energy prices and their variance (e.g. Ferderer, 1996), uncertainty is likely to be smaller in the post-1986 period. As this may also affect the responsiveness of Dutch industry to changes in energy prices (and hence to taxation), the impact of uncertainty should be analyzed. To explore the consequences of irreversibility and uncertainty for the environmental effectiveness of energy taxation in the Netherlands, the mechanisms behind asymmetric responses are elucidated through the use of a simple investment model presented in section 3.

On the basis of this model we show that, following a period of energy price increases, prices will have to drop substantially before energy-saving technologies are to be replaced by energy-intensive ones. This drop is likely to be larger (i) the higher the adjustment costs, (ii) the faster energy prices are expected to increase over time and (iii) the higher uncertainty about future prices. In turn, this means that energy price recoveries will not have much impact on energy use, suggesting that energy policy in periods of low energy prices will not be very effective.

In the next section we take a look at the data to find some evidence for asymmetries. Section 3 presents a theoretical model which shows that there are threshold effects to explain these asymmetries. In section 5, an empirical analysis is undertaken for eight sectors of Dutch industry to estimate these threshold effects. Section 6 concludes.

\footnotetext{
${ }^{2}$ On average, the (economic) lifetime of a installed capital is about 15 to 20 years.
} 


\section{Some stylized facts}

The theory presented in the next section has clear implications for energy policy in periods of relatively low energy prices that we would like to test empirically. Concerning the empirical analysis, we focus on the sectoral level because of the lack of time-series data at the firm level. Theory predicts that at the sectoral level, more substitution will take place in periods where energy price increases result in "all time highs" than in periods of low prices, where increases will be mere price recoveries. Changes in the technology used by individual firms will show up in the sectoral data as input substitution. Therefore, substitution elasticities are expected to be higher in energy price booms than in slumps. Furthermore, new technologies may result in efficiency gains. Little investments aimed at increasing energy performance are expected to take place in periods of low energy prices, and therefore technological progress is likely to be lower especially in energy-saving technologies.

Therefore, the prediction would be that in the post-1986 period (characterized by relatively low energy prices) neither the substitution elasticities between the various inputs nor the rates of technological progress would be substantial, implying that energy taxation may not be an effective instrument in the post-1986 period. However, there are two mitigating forces. The size of the "inertia price region" is smaller the lower the expected rate of energy price increases, and also the smaller the uncertainty about future energy prices. In the post1986 period energy prices have recovered only slowly, and there are even periods where energy prices were observed to fall. Concerning uncertainty with respect to future levels of energy prices, the energy price level is often positively correlated with the variance of energy prices: relatively high prices are generally more volatile than relatively low prices (Ferderer, 1996). This implies that the size of the inertia gap is expected to be smaller in the post-1986 period than in the pre-1986 period, and hence that the production structure of the Dutch economy would be more sensitive to changes in the relative prices of the various inputs.

In this section we aim to test the degree of substitutability of the various inputs (energy, labour and capital) and to analyze the type of technological progress (labour-saving, capital-saving or energy-saving) in response to changes in the relative prices of the various inputs. Figure 2 shows the energy-capital ratio for the sectors in our panel. In general, the energy-capital ratio declines until the mid-eighties. This decline may be caused by either input substitution or by energy-saving technological progress (or both).

< Insert Figure 2 about here >

From Figure 3 we can observe that the energy-labour ratio tends to increase for most of the sectors of industry our panel. Possibly, labour-saving technological progress dominates. 
< Insert Figure 3 about here >

In order to allow for different substitution elasticities, nested CES functions will be estimated. ${ }^{3}$ We have gathered data on a panel of eight sectors of industry for the Dutch economy. These sectors are agriculture, food and beverages, textiles and clothing, paper industry, basic metal industry, building materials, chemical industry and construction. These sectors are chosen on the basis of data availability for a longer time period. Data on energy use and energy prices are not (yet) available for the period before 1973 and after 1994 (at least not measured in a consistent way with the 1973-1994 period), so we restricted the time period to the period 1973-1994. ${ }^{4}$ Applying iterative weighted least squares analysis while assuming common effects, ${ }^{5}$ we estimated the model for three different periods: the entire sample period, and the sub-periods of price increases (1974-1986) and of price decreases (1986-1994). The actual results of the regression are presented in Kuper and Van Soest (1999); the most important results are summarized in Table 1.

Table 1 Summary of the parameters found for the various estimation periods

\begin{tabular}{|l|ccccc|}
\hline & Elasticities of substitution & \multicolumn{3}{l|}{ Technical progress } \\
\hline Period & capital vs energy & $\begin{array}{l}\text { capital/energy } \\
\text { vs labour }\end{array}$ & $\begin{array}{l}\text { Labour- } \\
\text { augmenting }\end{array}$ & $\begin{array}{l}\text { Capital- } \\
\text { augmenting }\end{array}$ & $\begin{array}{l}\text { Energy- } \\
\text { augmenting }\end{array}$ \\
\hline $1974-1994$ & $0.000492^{*}$ & 0.488788 & 0.025149 & -0.000529 & 0.023600 \\
$1974-1986$ & 0.000634 & 0.504730 & 0.030439 & -0.000895 & 0.041803 \\
$1986-1994$ & $-0.000354^{*}$ & 0.457320 & 0.014774 & $0.000049^{*}$ & $-0.003842^{*}$ \\
\hline
\end{tabular}

Not significantly different from zero at $5 \%$.

Concerning the entire sample period, capital and energy are found to be complements (the elasticity of substitution between capital and energy is found to be very close to zero or even insignificant) while the capital/energy mix and labour are found to be substitutes (the elasticity of substitution is less than 1). Furthermore, over this period technological change

\footnotetext{
${ }^{3}$ The model is discussed in detail in Kuper and Van Soest (1999). This paper is available at http://www.eco.rug.nl/medewerk/kuper

${ }^{4}$ There are three main sources of the data: volumes and prices of value added and labour are taken from the P-series of the National Accounts 1997 of CBS Statistics Netherlands (CBS, 1998). Data on the stock of capital in 1990-prices are provided by the CPB, Netherlands Bureau for Economic Policy Analysis. Data on the use of energy and the price of energy are based on the publication De Nederlandse Energiehuishouding (CBS, various issues). Some data series had to be constructed; the methodology applied is described in Appendix A.

${ }^{5}$ That is, no sector specific dummies have been included. Apart from running common effects panel estimations, we also ran fixed effects estimation regressions (thus allowing for sector-specific results). These are presented in Kuper and Van Soest (1999).
} 
has been fairly substantial for labour and energy. The capital-augmenting technology parameter is very close to zero, but this is probably caused by the complementarity of capital and energy. ${ }^{6}$ On the basis of this regression one may conclude that energy pricing policies are expected to be fairly effective: input substitution and technological progress are fairly large.

However, subdivision of the entire sample period in a period of general price increases (1974-1986) and decreases (1986-1994) contradicts this conclusion: the coefficient estimates differ substantially between the two sub-periods discerned. In the period of increasing prices, the elasticity of substitution between capital and energy is low but significantly different from zero, while it became insignificant in the period of price decreases. Furthermore, in the first period technical progress in labour was slightly above 3\% and in energy use even over $4 \%$. In the period of price decreases, labour-augmenting technological progress fell to less than $1.5 \%$ and energy-augmenting technical progress even fell to zero. This suggests that indeed the two periods differ: an asymmetry exists between periods of high and increasing energy prices (where technological progress and the elasticity of substitution are fairly substantial) and periods of low energy prices (where both technological progress and substitution elasticities are low). This implies that it is very likely that an increase in the price of energy through taxation is not going to generate a substantial reduction in energy use. That means that estimating the effectiveness of energy taxation on the basis of the entire post-1973 period is likely to yield an overestimation of the true effectiveness.

\section{Implications of investing under uncertainty for responses to energy price changes}

In this section, an illustration is provided why asymmetric reponses to energy price changes referred to in the previous section may arise. The main features causing the asymmetric response are the sunk-cost nature of investments in new technologies, exacerbated by the existence of uncertainty about the future. Suppose that there are two alternative technologies available for firms. A given quantity of goods can be produced by either an energy-intensive or a labour-intensive technology. Suppose that inputs for the energy-intensive technology are $E_{l}$ units of energy, and $L_{l}$ units of labour, while the corresponding inputs for the labourintensive technology are $E_{2}$ and $L_{2}$, respectively. From the assumption it is clear that $E_{1}>E_{2}$ and $L_{1}<L_{2}$. For notational convenience, define $\Delta E=E_{1}-E_{2}$ and $\Delta L=L_{2}-L_{1}$. Furthermore, assume that the adjustment costs $\left(C_{A}\right)$ from switching either from the energy-intensive to labour-intensive technology or vice versa, are the same. ${ }^{7}$

\footnotetext{
${ }^{6}$ Another explanation may be the continuous reductions in labour time, implying a lower utilization rate of capital.

${ }^{7}$ Note that this assumption seems unnecessarily restrictive. However, dropping it would have clear-cut consequences for the qualitative results derived in this section. If adjustment costs from energyintensive to energy-saving technologies are higher than the reversal (which seems plausible because of,
} 
With respect to the prices of both types of inputs, we assume that the price of labour $(W)$ is constant and known throughout, but that future energy prices $\left(P_{E}\right)$ are uncertain. Since most types of energy currently employed come from depletable resources, we assume a time trend for prices, but disturbances may force the energy price to deviate from its trend path. More specifically, the energy price is assumed to follow a Brownian motion:

$$
d P_{E}=\alpha P_{E} d t+\sigma P_{E} d z
$$

In this equation, $\alpha$ is the trend parameter and $d z=\varepsilon \sqrt{d t}$, where $\varepsilon$ is a normally distributed independent variable with a zero mean and a standard deviation of 1 . This implies that $\mathrm{E}\left(d P_{E}\right)=\alpha P_{E} d t$ with variance $\sigma^{2} P_{E}^{2} d t$ (Dixit and Pindyck, 1994, p. 70-71). Therefore, the expected energy price at time $t$ equals:

$$
\mathrm{E}\left(P_{E}(t)\right)=P_{E_{0}} e^{\alpha t}
$$

Now the costs and benefits of switching from the energy-intensive technology to the labourintensive technology can be determined. The change in technology results in savings on energy expenses, but expenditures on labour increase. Taking into account the adjustment costs $C_{A}$, the value of switching to labour-intensive (and hence energy-saving) technology equals:

$$
\Omega^{E S}\left(P_{E}\right)=\int_{0}^{\infty} \mathrm{E}\left(P_{E}\right) \Delta E e^{-r t} d t-\frac{W \Delta L}{r}-C_{A}=\frac{P_{E} \Delta E}{r-\alpha}-\left(\frac{W \Delta L}{r}+C_{A}\right),
$$

where $r$ is the (exogenously determined) discount rate. ${ }^{8}$

After implementing the labour-intensive technology, the firm may decide to reverse its investment if the price of energy is sufficiently low (see below). For a certain energy price level $P_{E}$, the value of this reversal option equals:

$$
\Omega^{E I}\left(P_{E}\right)=\frac{W \Delta L}{r}-\int_{0}^{\infty} \mathrm{E}\left(P_{E}\right) \Delta E e^{-r t} d t-C_{A}=\frac{W \Delta L}{r}-\left(\frac{P_{E} \Delta E}{r-\alpha}+C_{A}\right),
$$

What energy price is sufficiently high to induce the firm to switch towards the energy-saving (i.e. labour-intensive) technology? In each period, the firm compares the benefits of undertaking the investment (in terms of cost reductions achieved) with the benefits of postponing the decision one period. The latter include access to more information about

for instance, uncertainty with respect to the performance of new technologies and maybe also because of environmental regulations requiring emission cleaning activities), the conclusions of this section will only be strengthened.

${ }^{8}$ The results have been derived using dynamic programming, which is based on the assumption that the price risk cannot be spanned by constructing an appropriate market portfolio. If we would have dropped this (implicit) assumption, contingent claims analysis could be used which would have enabled us to derive a risk-adjusted discount rate. Using the capital asset market pricing approach, this discount rate would be equal to $r+\phi \rho_{P M} \sigma$, where $\phi$ is the market price of risk and $\rho_{P M}$ the correlation coefficient between market risk and the riskiness of the energy price (see Dixit and Pindyck, 1994, p. $185)$. 
energy prices. Given the uncertainty that the firm faces, postponing the decision reduces the probability of investing while such an investment turns out to be unprofitable. In mathematical terms, the firm maximizes:

$$
F^{E S}\left(P_{E}\right)=\max \left\{\Omega^{E S}\left(P_{E}\right), \frac{1}{1+r d t} \mathrm{E}\left(F^{E S}\left(P_{E}\right)+d F^{E S}\left(P_{E}\right)\right)\right\} .
$$

The value $\Omega^{E S}\left(P_{E}\right)$ is labeled the "termination value". When the firm decides to undertake the investment, its expected return is known. The expected return of waiting (the second term in the brackets) is usually referred to as the "continuation value". The firm's optimal decision maximizes the net present value of the investment option $F^{E S}$. As soon as the termination value exceeds the continuation value, the investment is undertaken. The energy price for which this is just the case will be referred to as the critical energy price $P_{E}^{E S^{*}}$.

Applying Ito calculus, the following differential equation is obtained:

$$
r F^{E S} d t=\mathrm{E}\left[F_{P}^{E S} d P_{E}+\frac{1}{2} F_{P P}^{E S}\left(d P_{E}\right)^{2}\right]=\left[F_{P}^{E S} \alpha P_{E}+\frac{1}{2} F_{P P}^{E S} \sigma^{2} P_{E}^{2}\right] d t .
$$

Try $F^{E S}=A P_{E}^{\beta}$. Solving the differential equation, two roots can be found:

$$
\beta=\left(\frac{1}{2}-\frac{\alpha}{\sigma^{2}}\right) \pm \sqrt{\left(\frac{1}{2}-\frac{\alpha}{\sigma^{2}}\right)^{2}+\frac{2 r}{\sigma^{2}}} .
$$

This term captures the impact of price uncertainty on the critical energy price level at which the switch towards the energy-saving technology will be carried out. The general solution is of the form $F^{E S}\left(P_{E}\right)=A_{1} P_{E}^{\beta_{1}}+A_{2} P_{E}^{\beta_{2}}$ where $\beta_{1}$ and $\beta_{2}$ represent the positive and negative roots respectively. The higher the energy price, the higher the value of the energy-saving investment option. This implies that the term with the negative root can be ignored: $A_{2}$ equals zero. Then the critical value of the energy price can be determined by using two additional conditions (Dixit and Pindyck, 1994; Pindyck, 1991). First, in the optimum it must hold that at the critical energy price level, the value of the investment project is equal to the termination value: $F^{E S}=\Omega^{E S}$ : given the fact the investment is undertaken, waiting apparently no longer has a positive net value (see equation 5). In the second place, optimality requires that the option value function $F^{E S}$ and the termination value function $\Omega^{E S}$ meet tangently at the critical price level: $F_{P}^{E S}=\Omega_{P}^{E S}$. Using these two additional conditions, it can be found that

$$
P_{E}^{E S^{*}}=\left(\frac{\beta_{1}}{\beta_{1}-1}\right)\left(\frac{r-\alpha}{\Delta E}\right)\left[\frac{W \Delta L}{r}+C_{A}\right] .
$$

Note that according to the NPV rule, the investments would be carried out as soon as:

$$
\frac{P_{E} \Delta E}{r-\alpha}>\frac{W \Delta L}{r}+C_{A} .
$$


The critical value under uncertainty, irreversibility and flexibility with respect to the timing of the investment decision exceeds the NPV's critical value because $\frac{\beta_{1}}{\beta_{1}-1}>1$ as $\beta_{1}>1$.

After the switch towards the energy-saving technology, the energy price may fall such that the firm may decide to reverse its decision and to re-install an energy-intensive (but labour-saving) technology. In each period, it weighs the benefits of reversing now and the benefits of postponing the switch:

$$
F^{E I}\left(P_{E}\right)=\max \left\{\Omega^{E I}\left(P_{E}\right), \frac{1}{1+r d t} \mathrm{E}\left(F^{E I}+d F^{E I}\right)\right\} .
$$

Hence,

$$
r F^{E I} d t=\left[F_{P}^{E I} \alpha P_{E}+\frac{1}{2} F_{P P}^{E I} \sigma^{2} P_{E}^{2}\right] d t .
$$

Again, try $F^{E I}=A P_{E}^{\beta}$. Then,

$$
\beta=\left(\frac{1}{2}-\frac{\alpha}{\sigma^{2}}\right) \pm \sqrt{\left(\frac{1}{2}-\frac{\alpha}{\sigma^{2}}\right)^{2}+\frac{2 r}{\sigma^{2}}} .
$$

This time only the negative root $\left(\beta_{2}\right)$ plays a role: the lower the energy price, the higher the likelihood that the reversal will be profitable and hence the higher the value of the reversal option. Using $F^{E I}=\Omega^{E I}$ and $F_{P}^{E I}=\Omega_{P}^{E I}$, it can be found that

$$
P_{E}^{E I^{*}}=\left(\frac{\beta_{2}}{\beta_{2}-1}\right)\left(\frac{r-\alpha}{\Delta E}\right)\left[\frac{W \Delta L}{r}-C_{A}\right] \text {. }
$$

Note that, because $\beta_{2}<0,0<\frac{\beta_{2}}{\beta_{2}-1}<1$ and hence the calculated critical value is lower than the value indicated by the NPV approach.

\section{Threshold effects}

The analysis presented above implies that there is an asymmetry in the response to energy price increases and decreases. The existence of adjustment costs, high expected rates of energy price increases and uncertainty about future prices drive a wedge between the critical energy price for a switch towards labour-intensive technologies, and the critical price for its reversal. Hence, in response to a price increase, investments will be undertaken. But a subsequent (moderate) drop in energy prices will not induce the reversal towards the energyintensive technology.

This point is illustrated in Figure 4, where critical energy price lines are drawn for various time trends and for two levels of uncertainty $(\sigma=0.01$ and $\sigma=0.05)$. From Figure 4 it is clear that there is a gap (an area between the two critical energy price levels) where prices 
can fluctuate without firms adapting their production technologies. Expectations about future price developments play an important role in deciding whether or not to invest in energysaving technology. Indeed, the critical price lines demonstrate that a higher (expected) price trend induces the firm to invest sooner (although the reduction is not substantial), but more importantly that the energy price should be much lower before the firm will start contemplating to reverse its decision. The reason is that high trend values compensate for stochastic drops in the energy price. The reversal will thus only take place if the actual energy price is quite low: only then can it be expected to stay at a low level for a substantial period of time (see equation 1). Furthermore, the higher the uncertainty with respect to future prices, the longer a firm will postpone investing: the higher the uncertainty, the larger the inertia gap.

\section{$<$ Insert Figure 4 about here >}

This idea can also be illustrated in another way. Suppose that there are many firms in the industry; one hundred to be precise. Suppose that the change in labour use is identical for all firms and is equal to one unit, but that some firms are more energy-inefficient than others: some firms can only reduce energy consumption with half a unit while others can reduce it with 1.5 unit. Assume that all firms are uniformly distributed between $\Delta E=0.5$ and $\Delta E=1.5$. That means that as the energy price increases, some firms will decide to undertake the energysaving investments, but others will want to wait. This situation is plotted in Figure 5, where the number of firms using energy-saving technologies $\left(N_{E S}\right)$ is plotted on the vertical axis against the energy price level on the horizontal axis. In the numerical example with a low trend and low uncertainty $(\alpha=0.03, \sigma=0.01)$, the critical energy price $\left(P_{E}^{E S^{*}}\right)$ for the firm that can achieve the highest savings in energy use, is about 0.7 . If the energy price increases above that critical level, an increasing number of firms will implement the energy-saving technology. If the price continues to increase up to 2.0 , all firms eventually switch towards the energy-saving (labour-intensive) option. However, for a subsequent decrease in energy prices, at first none of the firms react and only after the energy price has fallen sufficiently (to less than 1.4 in this numerical example), firms reverse their investments and $N_{E S}$ falls. Suppose that the price of energy did not fall all the way to the point where all firms would have reversed their investments, but only to intermediate price levels. Then only few (or even maybe none) of the firms would have adapted their technologies yet and a subsequent price recovery would again not evoke any responses. This would mean that after a period of price increases followed by price decreases, energy policy would be less effective in inducing investments in energy-saving technologies. The switching functions have also been drawn for the case of a higher trend $(\alpha=0.07, \sigma=0.01)$ and for a higher level of uncertainty 
$(\alpha=0.03, \sigma=0.05)$. The inertia gap is again larger the higher the uncertainty of the energy price level and the higher the expected rate of energy price increase.

\section{$<$ Insert Figure 5 about here >}

From these two figures it is clear that the asymmetry in the response to energy price changes will increase with $\alpha$ and $\sigma$. If the upper critical level (i.e., switch towards labour-intensive technology) has just been attained, the firm will undertake the investment. However, to reverse that decision, the energy price should drop substantially. For a large range of price decreases, nothing will happen in terms of energy use. The size of the inertia gap is larger (i) the higher the expected rate of price increase and (ii) the more uncertainty about future price levels. Of course, adaptation costs $\left(C_{A}\right)$ also play a role: the higher these costs, the larger the inertia gap.

\section{Threshold estimation}

The implication of the analysis above is that regression functions are not identical across all observations in the sample: the response to energy price changes is typically asymmetrical. To avoid a arbitrary selection of threshold levels we estimate the threshold level using threshold regression methods with individual-specific fixed effects (Hansen, 1999). If we have a balanced panel of observations $(i=1, \ldots, n$ individuals and $t=1, \ldots, T$ time periods), we can write the equation of interest as: ${ }^{9}$

$$
y_{i t}=\mu_{i}+\beta_{1}^{\prime} x_{i t} I\left(q_{i t} \leq \gamma\right)+\beta_{2}^{\prime} x_{i t} I\left(q_{i t}>\gamma\right)+e_{i t}
$$

where $x_{i t}$ is a $k$-vector, and $q_{i t}$ is the threshold variable and $\gamma$ is the threshold, $I$ is an indicator function that has a value one if the argument is true and zero otherwise. The error term is iid with mean zero and finite variance which rules out lagged dependent variables. The threshold is estimated using least squares. The observations are first sorted on the threshold variable and the search for the threshold is restricted to specific quantiles (the more quantiles the finer the grid to which the search is limited). This reduces the number of regressions and still generates sufficiently precise estimates. Bootstrapping simulates the asymptotic distribution of the likelihood ratio test used to test whether the threshold effect is statistically significant under the null of no threshold: $\beta_{1}=\beta_{2}$.

In a first experiment we take as threshold variable the level of energy prices and define $y_{i t}$ as the rate of growth of gross output (value added including energy use) per worker $Q / L$ and $x_{i t}$ as a 4-dimensional vector of regressors, again in rates of growth, consisting of the ratio of the wage rate over the user cost of capital $(W / R)$, the ratio of the wage rate over the 
price of energy $\left(W / P_{E}\right)$, the capital intensity $(K / L)$, and the energy intensity $(E / L)$. This reduced-form specification illustrates the role of relative prices just as we did in a previous experiment reported in section 2 .

We have a balanced panel consisting of 8 sectors of industry and 16 years of observation (1979-1994). We specify 100 quantiles and use 300 bootstrap replications. Using the level of energy prices as threshold variable we did not find a threshold: the test statistic $F$ equals 20.2 (the $10 \%, 5 \%$ and $1 \%$ critical values are 25.1, 29.6 and 43.7 respectively) and the bootstrap p-value equals 0.23 . This means that we can not reject the null. Obviously prices did not drop enough to make firms reverse their earlier decision towards a more energy saving method of production. The threshold variable we have choosen in the experiment is the level of energy prices irrespective of the history of energy prices. What matters probably is the level of the energy price relative to its all time high (cf. Hamilton, 1996). More research is needed both on the specification of the model and on the threshold variable itself.

\section{Conclusions}

This paper aims to shed light on the effectiveness of environmental policy in periods of high and low energy prices. It is argued that while firms are likely to invest in energy-saving technologies when energy prices hit all-time highs, they are unlikely to reverse the investment in periods of lower energy prices. This implies that in periods of relatively low energy prices (after 1986), small increases in energy taxation will not induce any changes in the production structure. Therefore, energy taxes are not expected be a strong instrument of environmental policy in periods of low energy prices..

Using Hansen's 1999 threshold estimation technique we do not find threshold effects in the level of energy prices which seems to indicate that firms do not reverse the investment decision.

\footnotetext{
${ }^{9}$ It is possible to calculate multiple thresholds instead of one as in equation (14).
} 


\section{References}

Bacon, R.W., 1991, Rockets and Feathers: The Asymmetric Speed of Adjustment of UK Retail Gasoline Prices to Cost Changes, Energy Economics, 13(3): 211-218.

Bernanke, B.S., 1983, Irreversibility, Uncertainty, and Cyclical Investment, Quarterly Journal of Economics, 98(1): 85-106.

Berndt, E., Ch. Kolstad and J.-K. Lee, 1993, Measuring the Energy Efficiency and Productivity Impacts of Embodied Technical Change, The Energy Journal, 14(1): 33-59.

Borenstein, S., A.C. Cameron and R. Gilbert, 1997, Do Gasoline Prices Respond Asymmetrically to Crude Oil Price Changes?, Quarterly Journal of Economics, 112(1): 305-339.

CBS Statistics Netherlands, 1998, National Accounts 1997, Sdu/uitgeverij, The Hague.

CBS Statistics Netherlands, various issues, De Nederlandse Energiehuishouding, CBS, Voorburg/Heerlen.

Chang, K.-P., 1994, Capital-Energy Substitution and the Multi-Level CES Production Function, Energy Economics, 16(1): 23-26.

Dargay, J. and D. Gately, 1994, The Response of World Energy and Oil Demand to Income Growth and Changes in Oil Prices, C.V. Starr Center Economic Research Report no. 9431, New York University, New York.

Dixit, A.K. and R.S. Pindyck, 1994, Investment under Uncertainty, Princeton University Press, Princeton.

Ferderer, J.P., 1996, Oil Price Volatility and the Macroeconomy, Journal of Macroeconomics, 18(1): 1-26.

Gardner, Th.A. and F.L. Joutz, 1996, Economic Growth, Energy Prices and Technological Innovation, Southern Economic Journal, 62(3): 653-66.

Gately, D., 1992, Imperfect Price-Reversibility of U.S. Gasoline Demand: Asymmetric Responses to Price Increases and Decreases, The Energy Journal, 13(4): 179-207.

Hamilton, J.D., 1988, A Neoclassical Model of Unemployment and the Business Cycle, Journal of Political Economy, 96: 593-617.

Hamilton, J.D., 1996, Analysis of the Transmission of Oil Price Shocks through the Macroeconomy, University of California, San Diego, mimeo.

Hansen, B.E., 1999, Threshold Effects in Non-Dynamic Panels: Estimation, Testing, and Inference, Journal of Econometrics, 39, 345-368.

Kirchgässner, G. and K. Kübler, 1992, Symmetric or Asymmetric Price Adjustments in the Oil Market: An Empirical Analysis of the Relations between International and Domestic 
Prices in the Federal Republic of Germany, 1972-89, Energy Economics, 14(3): 171185.

Mork, K.A., 1989, Oil and the Macroeconomy when Prices go Up and Down: An Extension of Hamilton's Results, Journal of Political Economy, 97(3): 740-744.

Mork, K.A., Ø. Olsen and H.T. Mysen, 1994, Macroeconomic Responses to Oil Price Increases and Decreases in Seven OECD Countries, The Energy Journal, 15(4): 19-35.

Mory, J.F., 1993, Oil Prices and Economic Activity: Is the Relationship Symmetric?, The Energy Journal, 14(4): 151-161.

Pindyck, R.S., 1991, Irreversibility, Uncertainty, and Investment, Journal of Economic Literature, 29(3): 1110-1148.

Ryan, D.L., Y. Wang and Plourde, A., 1996, Asymmetric Price Responses of Residential Energy Demand in Ontario, Canadian Journal of Economics, 29: S317-S323.

Smyth, D.J., 1993, Energy Prices and the Aggregate Production Function, Energy Economics, 15(2): 105-110. 


\section{Appendix A Data construction}

Concerning the data used in this paper, three series had to be constructed: the prices and quantities of intermediate output from the first level $Z$ and the user cost of capital. The intermediate (composite) output in constant prices can be calculated as the nominal composite output divided by its price index. The value of the composite output in nominal terms equals nominal capital expenditures plus nominal energy expenditures:

(A.1) $\quad P_{Z} Z \equiv R K+P_{E} E$.

If we re-scale the prices such that in the base-year $P_{E}=R=1, K$ and $E$ can be calculated in base-year prices. Then composite output $Z$ is simply $Z=K+E$. This means that we can calculate the price index of this combined output $Z$ as a weighted average of the price indices of the constituent parts:

(A.2) $P_{Z}=\left(\frac{K}{K+E}\right) R+\left(\frac{E}{K+E}\right) P_{E}$.

Dividing expressions (A.1) and (A.2) yields the volume of input $Z$.

The (nominal) user cost of capital is not calculated in the usual way. ${ }^{10}$ Here, we made use of data on the stock of capital (measured in 1990-prices) kindly provided by CPB, Netherlands Bureau for Economic Policy Analysis. We constructed capital income resulting from production as the gross operating surplus corrected for wage income of self-employed, were self-employed earn the same wage rate as employees. The nominal rental price of capital is now simply calculated as capital income (in current prices) divided by the stock of capital in 1990-prices.

Finally, given data on the volume of labour input $(L)$, capital input $(K)$ and energy input $(E)$, and their respective prices $\left(W, R\right.$ and $P_{E}$ ), we can construct gross output in nominal terms as value added in nominal terms plus the value of the energy input: $P Q=W L+R K+P_{E} E$, where $W L+R K$ equals nominal value added.

\footnotetext{
${ }^{10}$ The most simple Jorgenson type of user cost of capital is $R=P_{I}\left(i-\Delta \log P_{I}+\delta\right)$, where $P_{I}$ is the purchase price of a unit of capital, $i$ is the (nominal) interest rate, and $\delta$ is the (constant) rate of depreciation.
} 
Figure 1 Energy prices $(1990=100)$ for eight sectors of industry of the Dutch economy for the period 1973-1994.

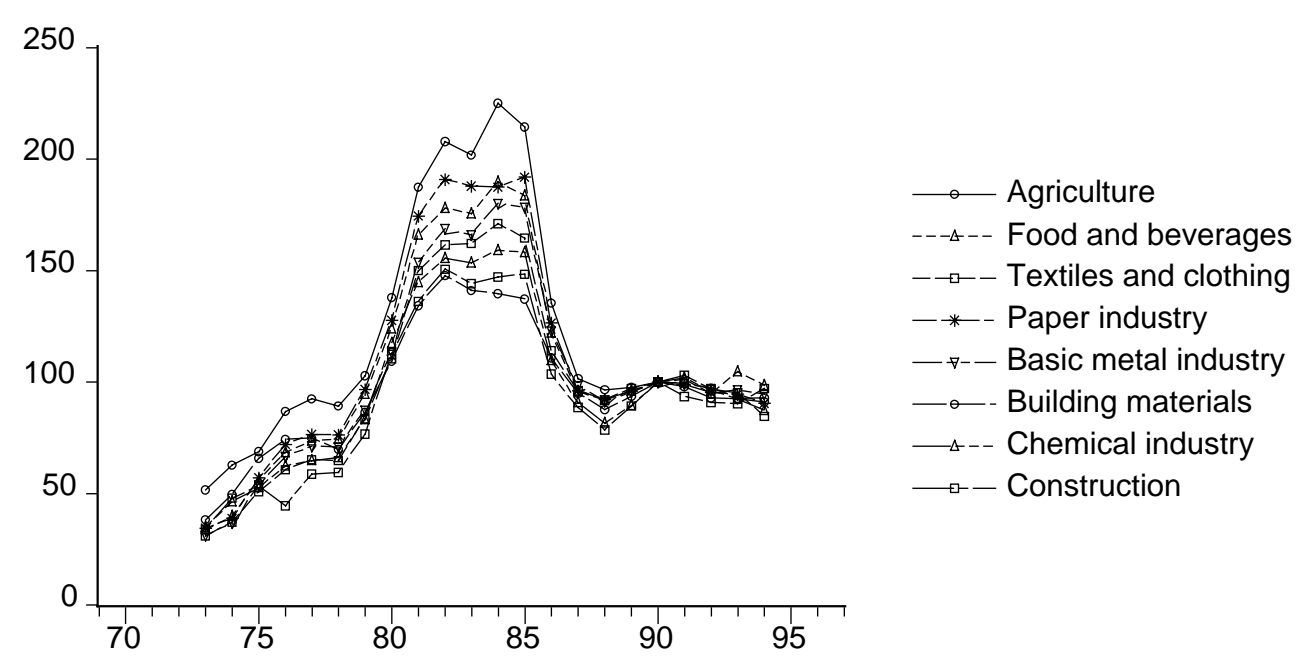


Figure 2 Energy-capital ratio for the sectors of industry in our panel.

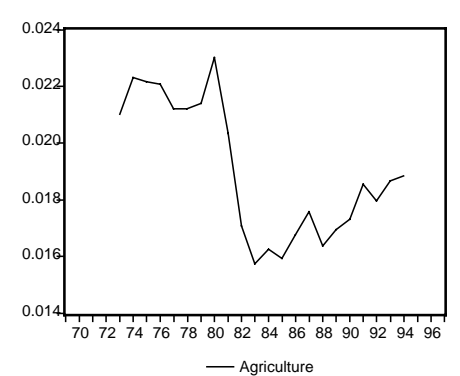

$$
\text { - Agriculture }
$$

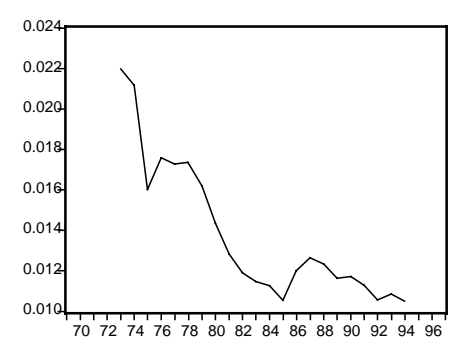

— Paper industry

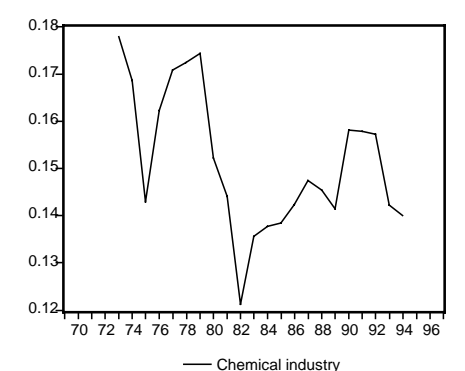

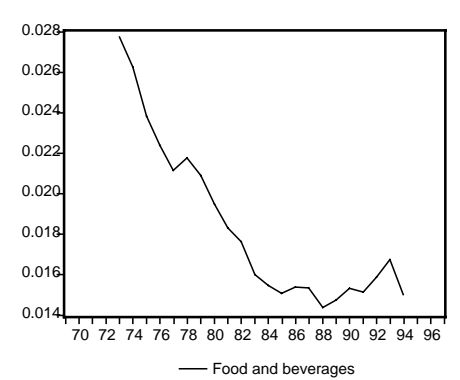

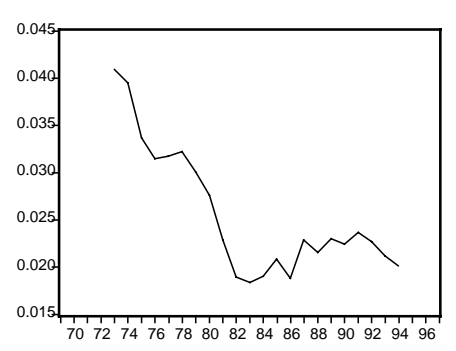

— Basic metal industry

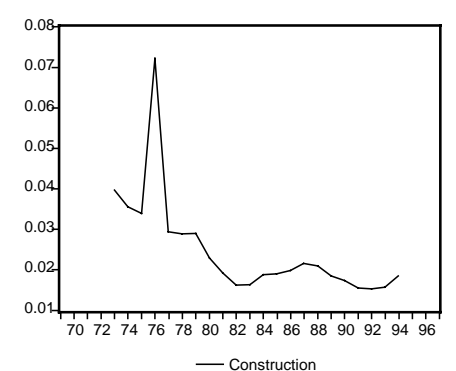

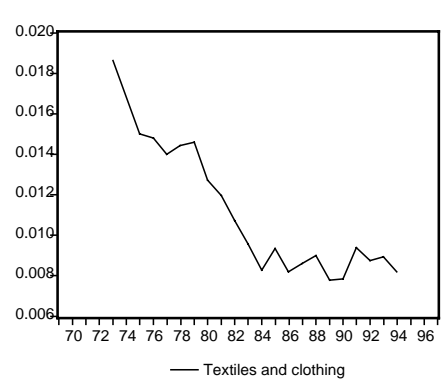

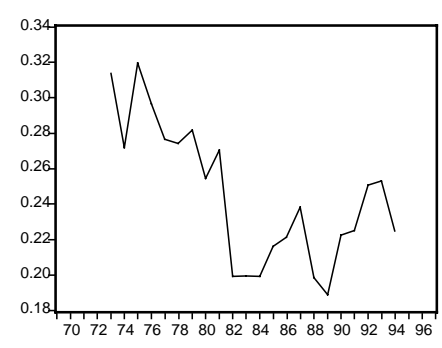

— Building materials 
Figure 3 Energy-labour ratio for the sectors of industry in our panel.

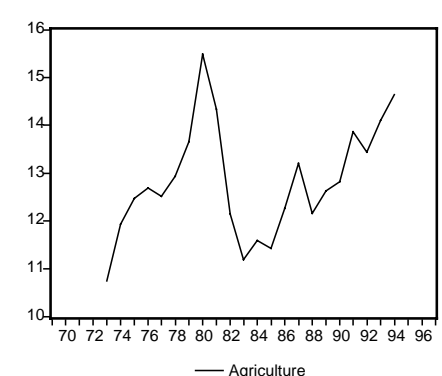

- Agriculture

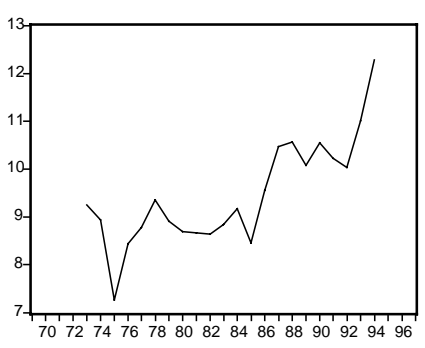

— Paper industry

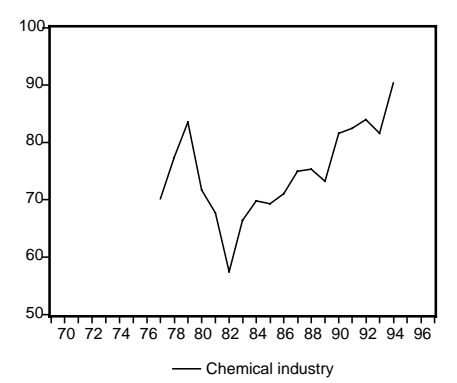

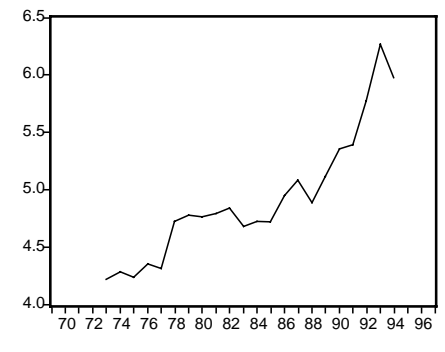

- Food and beverages

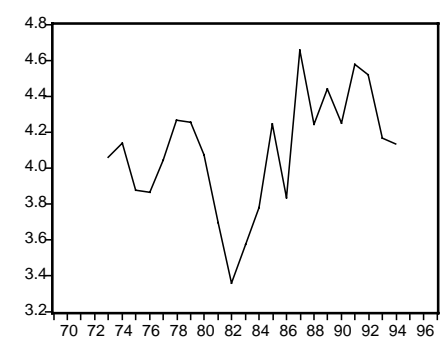

- Basic metal industry

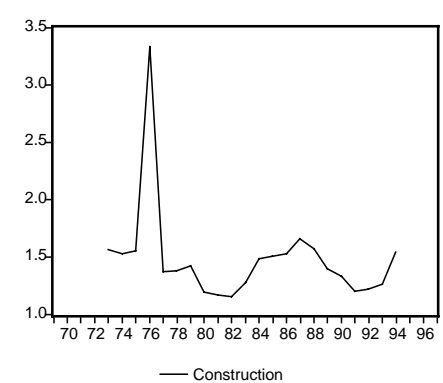

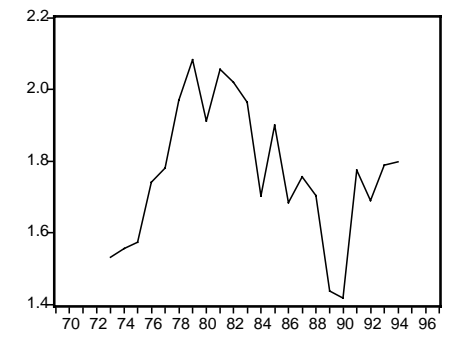

- Textiles and clothing

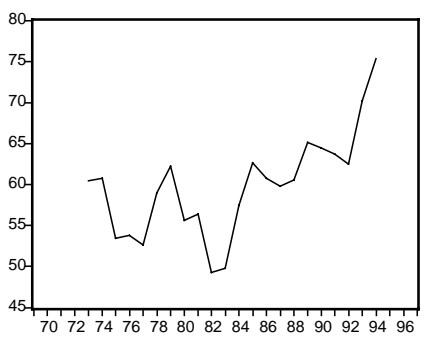

— Building materials 
Figure 4 Inertia price gaps as a function of the expected rate of energy price increases, for two different levels of uncertainty $(\sigma=0.01$ and $\sigma=0.05)$.

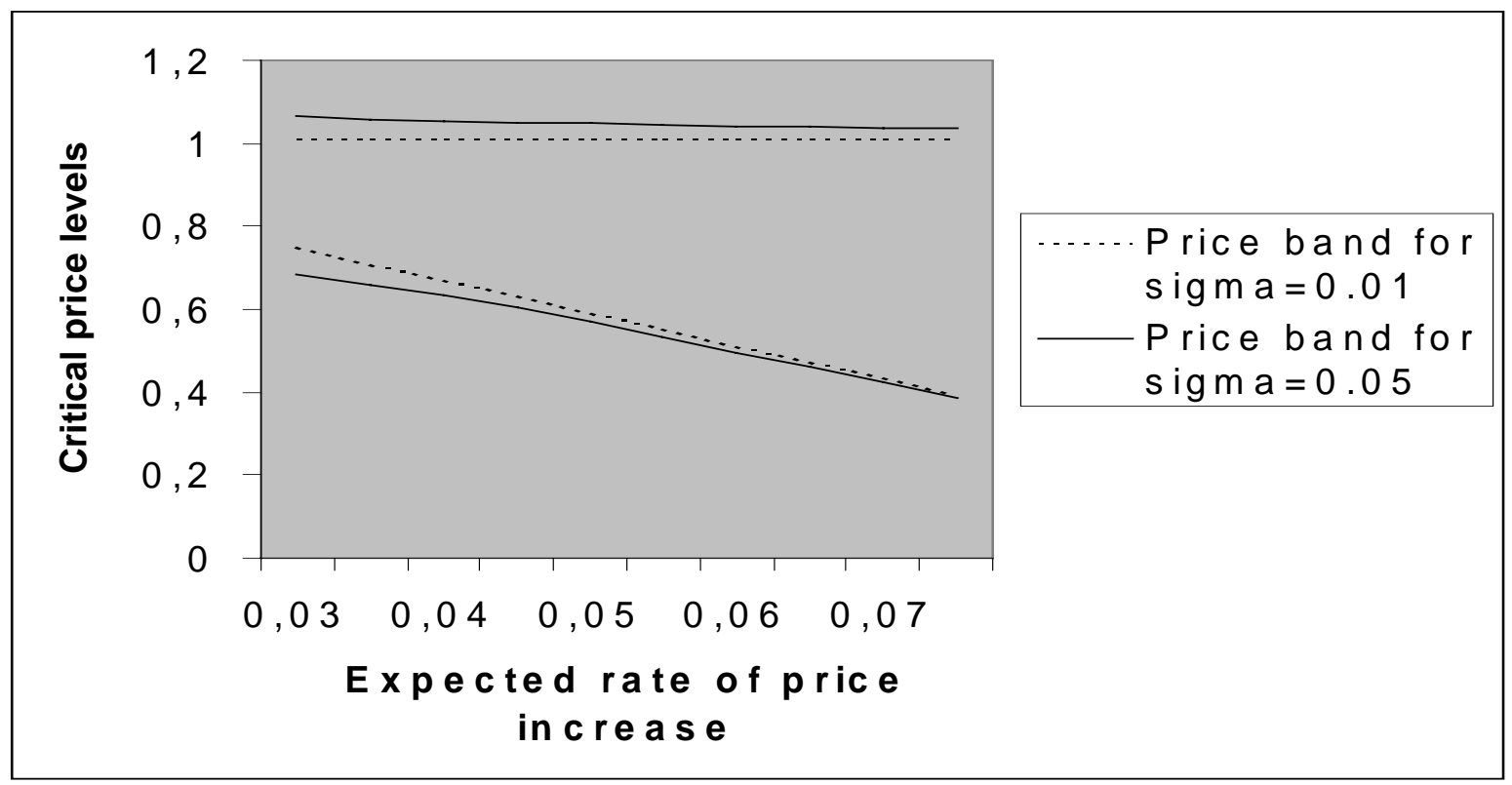

Parameter values: $\quad \Delta E=1, \Delta L=1, r=0.125, W=1, C_{A}=0.1$. 
Figure 5 The number of firms applying energy-saving technologies as a function of the energy price level for different combinations of expected rates of energy price increases and variances $(\alpha=0.03, \sigma=0.01 ; \alpha=0.07, \sigma=0.01 ;$ and $\alpha=0.03, \sigma=0.05$ ) for a price increase and subsequent decrease.

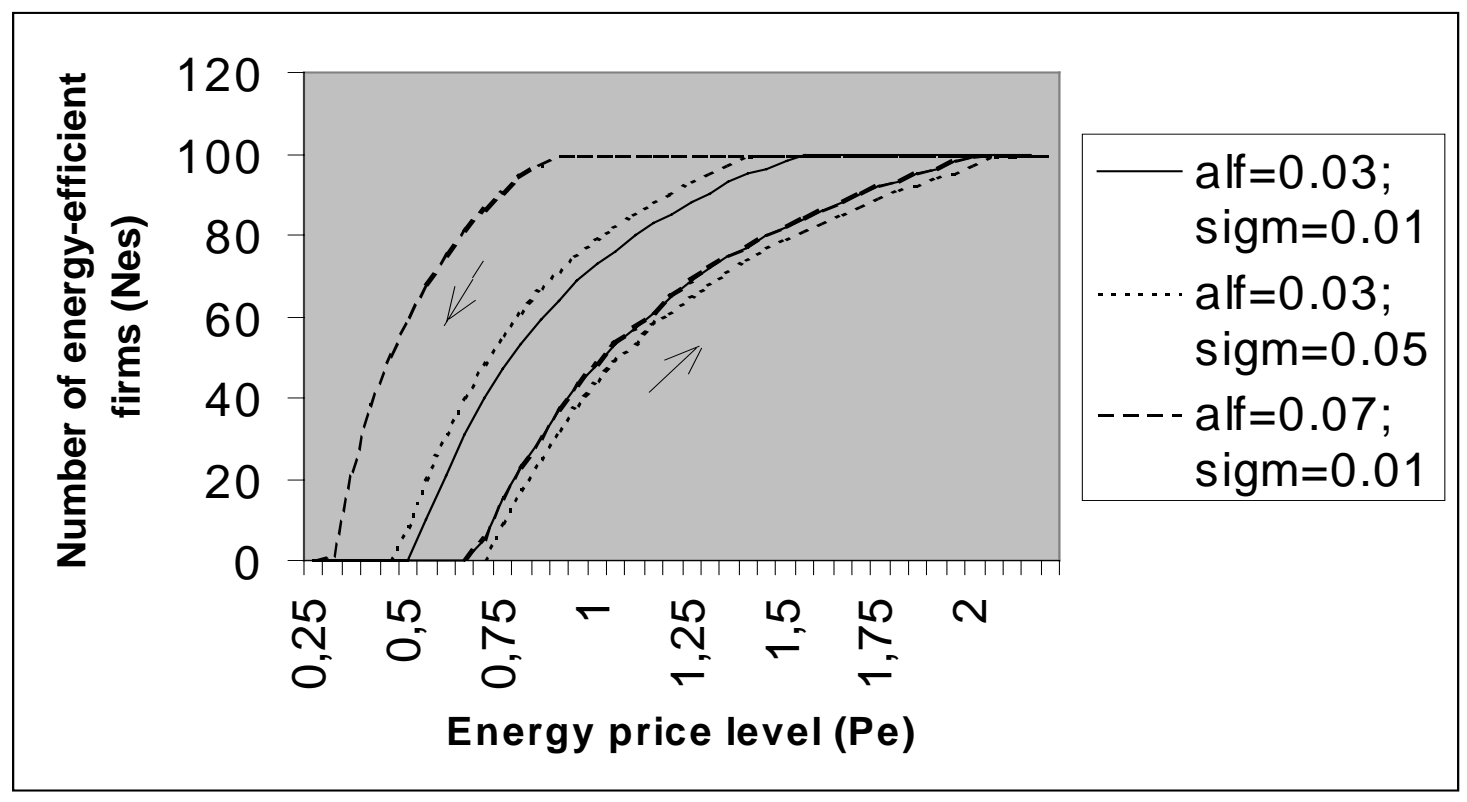

Parameter values: $\Delta E=1, \Delta L=1, r=0.125, W=1, C_{A}=0.1$. 